\title{
Cultural and Academic Meetings in the Writing Classroom: China and the West
}

\author{
Jane Mattisson Ekstam \\ Kristianstad University, Kristianstad, Sweden
}

\begin{abstract}
With growing numbers of Chinese students entering Western universities, cultural understanding is of increasing importance, not least in higher education. Without a good understanding of the academic conventions of Western universities, Chinese students, and undergraduates in particular, are at a disadvantage in the multi-cultural classroom. Lack of knowledge of structural influences on higher education, including teacher-student relations, reference management practices, and assessment procedures, are likely to lead to failure and disappointment. This paper, which is based on writing workshops conducted at Beijing University and in Sweden (Kristianstad University and Linnaeus University) in 2014, focuses primarily on writing practices and conventions because written texts are the main means of assessment in higher education. Addressing four key problems encountered by Chinese undergraduate writers in Western universities, namely lack of familiarity with the structure of academic papers, lack of focus on relevant issues, copying and pasting without giving proper reference, and inadequate understanding and mastery of the conventions of academic English, this paper argues for greater awareness of cultural differences between the Chinese and Western systems of education. Not until this has been achieved can Chinese students realize their full potential at Western universities.
\end{abstract}

Keywords: cultural awareness, mutual understanding, Chinese undergraduates, writing, assessment

\section{Introduction}

This paper argues for a greater awareness among Western and Chinese university teachers of cultural differences between the academic systems, particularly with regard to writing, the most important means of assessment in higher education. Cultural awareness is based on mutual understanding, which is explored not only in academic books and studies but also promoted by workshops of the kind discussed below. These were carried out in 2014 as part of a STINT (The Swedish Foundation for International Cooperation in Research and Higher Education) project that involved three universities: Kristianstad University (Sweden), Linnaeus University (Sweden), and Beijing University (China).

Sustainable social development places great demands on how teachers educate future generations. Education, and particularly higher education, has gradually become globalized. A successful exchange of students is beneficial in providing new experiences for outbound students and for furthering internationalization of education programs through incoming and returning students. The benefits of exchange are not limited to students alone: The presence of international students in university classrooms, Western as well as Chinese, has been compared to "canaries in the classroom" (Carroll \& Ryan, 2006, p. 3), an image harking back to 
19th-century mining practices when the canary was used to detect the presence of poisonous gas underground. International students are valuable indicators of the effectiveness of one's teaching: If an international student does not understand or perform well, it is likely that other students may also be experiencing difficulties. Nowhere is this more apparent than in writing classes: Without good writing skills and a thorough knowledge of the writing conventions of the host university, students are unlikely to succeed in their studies. The following discussion of writing is based on a series of academic writing workshops carried out in May and June 2014 at Beijing Normal University by teachers and researchers at Kristianstad University and Linnaeus University, Sweden. The focus of the workshops was on the structure and language of different kinds of academic texts, highlighting the main differences between the Chinese and Western systems. The primary aim was to explore potential areas of misunderstanding in order to prepare Chinese undergraduates for English studies at Western universities. While the organizers also learned much about the Chinese system of education and the opportunities for Western students to attend Chinese universities, the focus here is on Chinese undergraduates attending Western universities.

There are an increasing number of Chinese students at Western universities. Sweden is no exception. Between 2012 and 2013, nearly 8,000 students were admitted to Swedish universities from Asia, of whom over 2,000 were from China (incoming Chinese students accounted for approximately $20 \%$ of all incoming students to Sweden between 2012 and 2013; Sveriges Officiella Statistik, 2013). At the same time, however, it has also been noted that there has been a reduction of approximately $50 \%$ in the number of undergraduates entering Swedish universities from China in the past two years (dropping from 900 to 450 students; Sveriges Officiella Statistik, 2013). One major factor in this reduction is Chinese undergraduates' limited knowledge and experience of Western university studies, which has resulted in a high failure rate (approximately $30 \%$ of Chinese undergraduates fail courses in the humanities at Kristianstad University); this has discouraged Chinese students from applying to Western universities. It is essential that Chinese and Western teachers understand one another's academic/writing cultures as well as the expectations of the sending and receiving university in terms of, for example, classroom interaction, the relationship between teachers and students, the importance of critical thinking and writing, and different assessment procedures. When teaching undergraduates, the focus must be on highlighting the basic differences between Chinese and Western academic conventions particularly in the field of academic writing because Western traditions are so different and because written texts are the most common form of assessment in Western universities. While the learning curve is also steep for postgraduates, as identified by John Flowerdew (2007; Flowerdew focuses on the problems encountered by non-Anglophone scholars in publishing articles in journals), the problem is most serious at undergraduate level because most students have little or no prior experience of university studies. This situation must be addressed as many undergraduates wish to proceed to post-graduate studies.

Chinese students have consistently been represented as obedient, passive in class, and lacking critical thinking in research; this is often attributed to a shared cultural heritage rooted in Confucianism (Shi, in Clarke \& Gieve, 2006). Such an approach has been criticized for asserting rather than demonstrating the link between cultural values and learning practices as well as for relying mainly on reports and perceptions by Western instructors (Clarke \& Gieve, 2006). The problem is compounded by the fact that Chinese and Middle East Higher Education Institutions are seldom included in comparative studies (an exception is S. Chan (1999) who has noted that there are major differences between, for example, the North American and East Asian higher education systems with respect to the systems' main purpose, instruction mode, and curricular orientation). 
Higher education institutions involved in student exchange programs in these regions thus face several difficulties, not least in how to participate successfully in seminars or how to write an academic text.

In examining the ethnography of the modern subject, Kleinman and Fitz-Henry (2007) emphasize that experience is inter-subjective and involves practices, negotiations, and contestations with those to whom one relates. Being an international student is part of a meaning-making process and simultaneously involves the subtle forms of power that permeate education and learning activities. Power and meaning are not in theoretical opposition but intimately linked. Students are social actors who take part in constructing their learning community; they are not merely passive recipients of information. At the same time, they are subject to the rules and regulations in their home country and the new learning community in the host country. Their ability to take action is dependent on tangible resources and the opportunities available. Thus, positioning international students as agents involves considering the particularity of specific young people and local worlds while bearing in mind structural influences that both constrain and further student agency. What are these structural influences, and how do they need to be addressed in order to ensure successful Chinese-Western student exchange? This question forms the foundation of the ensuing discussion.

\section{Structural Influences}

In Western universities, the relations between teaching staff and students are much less hierarchical and formal than in Chinese universities and are based on the idea that relaxed relations promote exchange of ideas and independent thinking. The more informal relations and relatively fewer contact hours in Western universities can, however, be a problem for Chinese students who are used to meeting their supervisor often, sometimes even in the evenings or at weekends. The greater emphasis in Western universities on independent study is thus a special challenge for Chinese undergraduates, who need guidance, for example, in planning their time, making the best use of the library, identifying and annotating useful sources, and constructing new and interesting arguments and studies.

The differences in the role of the supervisor/teacher in China and in Western universities must also be addressed. As C. K. Chan and N. Rao (2010) point out,

although both Chinese and Western teachers feel that they have to promote academic development, Chinese teachers believe that they are also responsible for "cultivating students" and promoting development in non-academic areas. Chinese teachers regard teaching and learning as being more holistic than their Western counterparts, and see themselves as "moral educators" who help students to understand their roles in society. (pp. 9-10)

The chief concern of a Western supervisor, on the other hand, is to ensure that students fulfill the relevant criteria as stipulated in the syllabus.

\section{Assessment}

Chinese undergraduates are sometimes surprised to learn that attendance in class is not sufficient to achieve a pass grade in the West. They may need additional support when writing critical assignments that involve independent thinking. The emphasis on rote learning in China and on producing correct and complete answers as opposed to discussing possible ideas and interpretations also needs to be identified as a potential problem (cf. Su, Su, \& Goldstein, 1994; Xiao \& Dyson, 1999). The wider range of examination forms in Western universities, e.g., oral presentation, reports, take-home examinations, and formal written tests is also new to Chinese undergraduates: What are the major differences in terms of criteria and technique between these 
different forms? And how can students best prepare themselves? These are crucial questions that must be addressed in class at different stages of the academic term.

Assessment procedures must also be explained. What are, for example, the students' rights? In Sweden, students do not, for example, have the right to contest their grade but may, on the other hand, question the form of examination. Because Chinese students are unlikely to ask questions (this is seen as a sign of disrespect because in Chinese academic culture asking questions suggests that the teacher has not explained adequately), it may be necessary to anticipate problems and misunderstandings and address these in advance.

\section{Source Management, the Importance of Ethical Practice and Plagiarism}

Not all Chinese universities emphasize the importance of consulting and quoting from primary and secondary sources. As this is a pre-condition for academic validity in the West, Chinese undergraduates need considerable help in this area to ensure that they quote sufficiently but not excessively, and that they avoid plagiarism. The use of source detection programs such as Urkund, used in Swedish universities, may be new to Chinese undergraduates and must be explained, as must the consequences of plagiarism. This problem is discussed in greater detail below under the heading "Copying and Pasting Without Giving Proper Reference".

\section{Writing for Undergraduates}

The workshops in Beijing in 2014 established that there are four basic problems facing Chinese students learning to comply with the conventions of Western academic writing: lack of familiarity with the structure of academic papers, lack of focus on relevant issues, a tendency to copy and paste without giving proper reference, and inadequate understanding and mastery of the conventions of academic English. Each of these areas is discussed below.

\section{Lack of Familiarity With the Structure of Academic Papers}

Chinese students are not always familiar with the IMRAD structure, i.e., Introduction, Methods/Materials, Results And Discussion that is used in Western universities, primarily in physics and biology but also in the social and behavioral sciences. In addition, humanities students must learn to focus on readability and the clarification of nuances in the topic, where there is a less distinct separation of topic explication and exact data collection procedures than that required in the IMRAD structure. Chinese students may resist the IMRAD structure as they have been encouraged to develop a more personal and less standardized approach to structuring a text.

The workshops in Beijing and Sweden demonstrated the importance of explaining to Chinese students that the purpose of an IMRAD paper is to show whether or not a set of data supports—or does not support—an idea or opinion that is formed into a "hypothesis", "aim", "thesis statement", or "research question". It was also established that it is necessary to go through the content and purpose of each part of the IMRAD structure, focusing on the following: the importance of the introduction in explaining why the study was undertaken and what it is about with the aim of awakening the reader's interest, providing sufficient detail about the methods and materials to provide a proper contextualization of the subject and enabling assessment of the results and replication of the study, demonstrating to what extent the results provide an answer to the research question, and discussing these in connection with the relevant secondary sources including linking the results to previous research as well as pointing to future research. 
Because the IMRAD structure focuses on analysis (as opposed to description) using models, it places great emphasis on independent critical thinking and relies on deductive rather than inductive thinking. This poses special problems for Chinese students.

\section{Lack of Focus on Relevant Issues}

As a high-context culture, China places great emphasis on the background of the issue that is being discussed instead of on the argument itself. As a result, students may produce reports, essays, and theses that to a Western teacher appear to focus on less relevant issues or, indeed, perhaps even lack focus. There is a clash of academic traditions here as "Asian cultural and educational systems emphasize a view of knowledge as that which should be conserved and reproduced, in contrast with Western systems, which emphasise a more speculative, questioning approach" (Kirby, 1996, p. 142). When it comes to student essays, Chinese undergraduates must learn that it is important to state the issue addressed in the introduction. At the workshops in Sweden and Beijing, the Purdue Online Writing Lab was recommended, which gives useful advice on how to write an effective introduction and how to link it to the methods and materials section.

The workshops also demonstrated that special attention needs to be paid to avoiding extreme subjectivity. While Chinese students must be encouraged to develop critical thinking, such subjective expressions as "I think" and "I believe" must be avoided because they are likely to make the writer appear opinionated; they are also too colloquial for academic texts.

\section{Copying and Pasting Without Giving Proper Reference}

As is widely acknowledged, free access to information on the Internet has created special problems in higher education when it comes to ethical source management. The Chinese teachers attending the workshops reported major problems among their students with copying and pasting information without proper critical analysis and without giving a proper reference. It is necessary to teach undergraduates how to summarize and to re-write source material in their own words. The problem of stacking quotations, i.e., listing one quotation after the other without proper analysis must also be addressed. Not all Chinese universities teach how to reference and analyze quotations. Carol Bailey (2005), when writing about Chinese students at UK universities, explains, for example, that

students writing an undergraduate dissertation in China are advised (but not required) to state their sources at the end of the dissertation; however they are not required (or taught) to use quotation marks, paraphrase and in-text referencing within the body of their work. For an undergraduate essay, no form of referencing is required at all. (p. 11)

She goes on to describe how in China even textbooks and scholarly articles may lack referencing; it is thus not surprising that the differences in referencing practices create special difficulties for Chinese students in the West. Carol Bailey (2005) concludes that "the misapplication or transgression of 'western' academic writing conventions is the single greatest cause of failure by Chinese students at my university [University of Wolverhampton]" (p. 27). The situation at Wolverhampton is shared by many Western universities.

A slightly different view is expressed by Swedish professor Diane Pecorari (2013), who questions the explanation of plagiarism in terms of cultural differences. Instead, she suggests that international students are, in fact, very similar to home students in that they find academic language and conventions difficult to master, but because English is not their native language, "they have further to go to close the gap between their current skills and those they need to develop" (Pecorari, 2013, p. 114). She suggests that teachers must recognize international students' need for clear explanations and illustrations of what plagiarism means, and how it is 
handled at their university. Some of the ways in which teachers can support international students in their attempt to manage sources include reading academic texts, reformulating ideas from them, using reporting verbs, and providing opportunities for practice, feedback, and revision. It is also important that teachers are open to the possibility that "plagiarism can have non-deceptive causes" and are willing "to extend the presumption of innocence" to their students (Pecorari, 2013, p. 115). Whatever one's views of the origins of referencing problems, it is clear that proper explanations, repeated at regular intervals, are essential if students are to develop ethical referencing practices and avoid plagiarism.

\section{Inadequate Understanding and Mastery of the Conventions of Academic English}

The workshops in Beijing and Sweden suggested that in terms of the conventions of academic English, the following are of particular importance for Chinese undergraduates: cohesive devices, paragraph divisions, topic sentences, punctuation, and the use of the definite/indefinite article. Students must understand that academic English is different from everyday spoken English. As Kirby (1996) argues, the academic context can be thought of as "a second — and even third — culture, with language as one of its central features" (p. 143). They go on to describe academic discourse as "information focused" and "decontextualized", whereby "information is expressed in isolation from supporting cues in the environment, using complex syntactic structures and specialized vocabulary" (p. 143). This means that specialized language skills are needed to understand and produce academic texts. Because argumentative or expository texts are unlike narratives in that they rely on certain rhetorical structures that convey the logical sequence of events, cohesive devices and transitional words must be used to create fluency in an academic text. These need to be identified and taught with the aid of examples such as the following:

Contrast: But, however, on the other hand, yet

Illustration: For example, that is

Extension: In addition, by extension, what is more

Conclusion: Therefore, consequently, as a result, thus

Indicating the next step: Then, after that, it follows

Students may be referred to secondary sources such as Bryan Greetham's How to Write Better Essays (2001).

The workshops also identified the tendency among Chinese undergraduates to overuse clichés ("every coin has two sides"; "a double-edged sword" were specifically mentioned) and propaganda phrases. Chinese undergraduates, like their Western counterparts, may believe that academic style entails using unusual words, figurative language, or long, complicated sentences rather than the precise, clear, and neutral descriptions that are actually required.

The Chinese teachers at the workshops also noted the lack of clear topic sentences in their students' work. This problem is related to a lack of understanding of the purpose of a paragraph. Chinese undergraduates need to be taught that a paragraph has one of seven different purposes: to show that the writer is switching to a new idea; highlight an important point by putting it at the beginning or end of a paragraph; mark a change in time or place; emphasize a contrast; indicate a change of speakers in a dialogue; give readers an opportunity to pause, and finally, to break up a dense text. Students require extensive practice in writing topic sentences.

Another area identified as presenting special problems for Chinese undergraduates is punctuation because the latter is not used in Chinese. The comma is a case in point. Its use in lists and before a defining relative 
clause needs to be taught and practiced. Lynne Truss's Eats, Shoots and Leaves (2003) is a particularly useful reference here. The colon also presents a problem. It is not sufficient to explain its function; students need to be given practice in using it in different contexts. They should also be encouraged to note how the colon is used in printed texts. Another problem identified in the workshops was the use of run-on sentences, which the grammar checker does not always identify. The apostrophe was also mentioned, and particularly the use of the genitive form. Definite and indefinite articles are notoriously problematical for Chinese students. Students who find it difficult to understand how to use articles in English can usefully consult an English grammar book, such as English Grammar: Theory and Use (2012), Longman's Student Grammar of Spoken and Written English (2002) in addition to the online sources listed in the works cited list below. Diane Hacker and Nancy Sommers' $A$ Writer's Reference (2011) and her Exercises for A Writer's Reference Compact Format (2010) were also discussed at the workshops in Beijing and Sweden.

The above-defined problems should not only be addressed by teachers but also by fellow students, so-called peer reviewers. Because, however, Chinese students are used to seeing their teacher as the source of all knowledge, they are not always keen to consult with their fellow students. For this reason, the advantages and disadvantages of peer reviewing were discussed at length at the workshops. It became clear that the system is not widely used in Chinese universities.

\section{Peer Reviews in the Cross-Cultural Classroom}

Studies have demonstrated that Chinese learners of English make more corrections based on teacher feedback than they do on peer feedback (Connor \& Asenavage, 1994). However, Miao (2006) found that peer feedback led to a greater degree of "meaning-change revision" whereas teacher feedback revisions take place "at surface level" (p. 193). They conclude that "teacher-initiated revisions are less successful than peer-initiated revisions, probably because negotiation of meaning during the peer interaction helps to enhance mutual understanding and reduce misinterpretation and miscommunication" (Miao, 2006, p. 193). Peer feedback thus has an important role to play in the writing classroom and should be introduced as early as possible.

Peer reviews may also have a positive effect on student autonomy. For students in a hierarchical academic system such as that of China, the method has special advantages. E. C. Berg (1999) has found that peer feedback may help encourage critical thinking: The student cannot just take the advice as given and make the change, as is likely when the expert, i.e., teacher provides feedback. Instead, the student will need to consider the advice from a peer, question its validity, weigh it against his or her own knowledge and ideas, and then make a decision about what, if any, changes need to be made (Berg, 1999, p. 232).

There are special challenges in using peer reviews in cross-cultural groups. As Allaei and Connor (1990) demonstrate, "conflict or at the very least, high levels of discomfort may occur in multicultural collaborative peer response groups" (p. 24). Carson (1994) found that students from different cultures had different expectations regarding such basic elements of the group situation as the roles of the members and the general interaction of members of the group. While it is essential that the teacher is aware of these challenges, it is clear that the rewards of cross-cultural work among peers greatly outweigh the drawbacks; it is thus advisable to mix nationalities. If students work in pairs, a simple peer review sheet that clearly states the most important points of the assignment facilitates a well-structured discussion. Written peer reviews not only provide structure but also perform a face-saving function for students who are not used to giving critique. 


\section{Conclusion}

While Chinese undergraduates are very much welcomed at Western universities, their presence poses problems in terms of different traditions in learning, teaching, and assessment as well as with respect to such structural factors as the relationship between teacher and students, the development of critical thinking and reference management practices.

The differences in the Western and Chinese systems become particularly apparent and indeed crucial in the area of academic writing as this is the primary tool of assessment and because Western and Chinese traditions are based on different modes of thinking. Punctuation poses special problems. And because in China the teacher is regarded as the fountain of all knowledge, Chinese undergraduates are suspicious of the peer review system.

It is crucial that Chinese teachers and students understand one another's cultures and academic practices and respect these while at the same time appreciating the importance of adaptation to the new culture. It is not a question of one culture being "better" than another but of accepting that Western and Chinese systems and practices are different. It is in writing classes that these differences become most clearly apparent. As long as teachers in the West continue to emphasize the importance of written production as a means of assessment, it is necessary to strive to produce the pre-conditions for success not only for Western but also for Chinese students. This entails developing awareness of cultural differences among both teachers and students. Mutual understanding creates mutual respect. It is to be hoped that Chinese students will not only continue to attend Western universities but that an increasing number of Western students will study at Chinese universities. Workshops of the kind carried out at Beijing Normal University and in Sweden are an important part of this process.

\section{References}

Allaei, S., \& Connor, U. (1990). Exploring the dynamics of cross-cultural collaboration. The Writing Instructor, 10, 19-28.

Bailey, C. (2005). "The UK lecturers don't teach me anything”: Chinese students' expectations of their teachers and implication for UK HE provision. In Conference Proceedings: The Chinese and South East Asian Learner: The transition to UK Higher Education (ss. 1-12). Southampton: Southampton Solent University.

Berg, E. C. (1999). The effects of trained peer response on ESL students' revision types and writing quality. Journal of Second Language Writing, 8(3), 215-241.

Biber, D., Conrad, S., \& Leech, G. (2002). Longman's student grammar of spoken and written English. London: Longman.

Carroll, J., \& Ryan, J. (2006). Teaching international students. Improving learning for all. London and New York: Routledge.

Carson, J. G. (1994). Writing groups: Cross-cultural issues. Journal of Second Language Writing, 3(1), 17-30.

Chan, C. K., \& Rao, N. (Eds.). (2010). Revisiting the Chinese learner: Changing contexts, changing education. CERC Studies in Comparative Education, 25.

Chan, S. (1999). The Chinese learner-A question of style. Education + Training, 41(6/7), 294-305.

Clarke, R., \& Gieve, S. (2006). On the discursive construction of "The Chinese Learner". Language, Culture and Curriculum, 19(1), 54-73.

Connor, U., \& Asenavage, K. (1994). Peer response groups in ESL writing classes: How much impact on revision? Journal of Second Language Writing, 3, 257-276.

Flowerdew, J. (2007). The non-Anglophone scholar on the periphery of scholarly publication. AILA Review, 20, 14-27.

Greetham, B. (2001). How to write better essays. Basingstoke: Palgrave.

Hacker, D., \& Sommers, N. (2010). Exercises for a writer's reference compact format. New York: Bedford/St. Martin's.

Hacker, D., \& Sommers, N. (2011). A writer's reference. New York: Bedford/St. Martin's.

Hasselgård, H., Johansson, S., \& Lysvåg, P. (2012). English grammar: Theory and use. Oslo: Universitetsforlaget. 
Kirby, J. R. (1996). Studying in a second language: The experiences of Chinese students in Canada. In D. A. Watkins, The Chinese learner: Cultural, psychological and contextual influences (pp. 141-158). Hong Kong: CERC and ACER.

Kleinman, A., \& Fitz-Henry, E. (2007). The experiential basis of subjectivity: How individuals change in the context of societal transformation. In J. Biehl, B. Good, \& A. Kleinman (Eds.), Subjectivity. Ethnographic investigations. Los Angeles: University of California Press.

Miao, Y. R. (2006). A comparative study of peer and teacher feedback in a Chinese EFL writing class. Journal of Second Language Writing, 15, 179-200.

Pecorari, D. (2013). Teaching to avoid plagiarism: How to promote good source use. Maidenhead and New York: Open University Press.

Purdue University. (n.d.). Purdue online writing lab. Retrieved form https://owl.english.purdue.edu/

Su, Z., Su, J., \& Goldstein, S. (1994). Teaching and learning science in American and Chinese high schools: A comparative study. Comparative Education, 30(3), 255-269.

Sveriges Officiella Statistik. Statistiska Meddalenden UF 20 SM 1302 (Sweden's official statistics. Statistical messages UF 20 SM 1302). (2013). Retrieved from https://www.ukambetet.se/download/18.575a959a141925e81d11e47/1403093615104/ Internationell-studentmobilitet-SM-1302.pdf

Truss, L. (2003). Eats, shoots and leaves. The zero tolerance approach to punctuation. New York: Gotham Books.

Xiao, Z., \& Dyson, J. (1999). Chinese students' perceptions of good accounting teaching. Accounting Education, 8(4), $341-361$.

Yin, H., Lu, G., \& Wang, W. (2014). Unmasking the teaching quality of higher education: Students' course experience and approaches to learning in China. Assessment and Evaluation in Higher Education, 39(8), 1-20. 